\title{
Eagle syndrome imaging: a case report
}

\section{Abstract}

The styloid process is a conical bone formation that comes from the base of the skull to the bottom of the mastoid, the stylohyoid ligament connects the tip of the styloid process to the little horn of the hyoid bone. Eagle syndrome is a radio-clinical entity characterized by ossification of the ligament stylohyoid giving a long styloid process exceeding $30 \mathrm{~mm}$ in length. This syndrome is characterized by a high variability semiologic. The objective of this work is to recall the clinical presentation of Eagle syndrome in order to evoke the diagnosis and show the radiological aspect of this often misunderstood entity through a clinical case.
Volume 10 Issue 5 - 2018

Ines Ben Hassen, Mohamed Habib Daghfous

Department of Radiology, Habib Thameur Hospital, Tunisia

Correspondence: Ines Ben Hassen, Department of Radiology, Habib Thameur Hospital, Tunis, Tunisia,

Email i.benhassen.zakraoui@hotmail.fr

Received: December 12, 2018 | Published: october 01, 2018

\section{Introduction}

Eagle syndrome is a radio-clinical entity characterized by ossification of stylohyoid ligament described by Eagle in $1937 .{ }^{1}$ This entity can manifest clinical signs related to compression of neurovascular structures in the vicinity, it affects $4 \%$ of the general population of which only $4 \%$ are symptomatic. L objective of this work is to recall the clinical presentation of Eagle syndrome in order to evoke the diagnosis and show the radiological aspect of this entity.

\section{Case report}

Patient 58 year old smoker, hypertensive, diabetic, dyslépidémique the history of ischemic cerebrovascular accidents for 10 years. CT angio TSA was performed as part of an exploration of atherosclerotic plaques objectified on Doppler ultrasound of TSA and accidentally shown an elongated styloid process measuring 33 last mmWG is closely related to the carotid artery external but also internal carotid artery Figure 1.

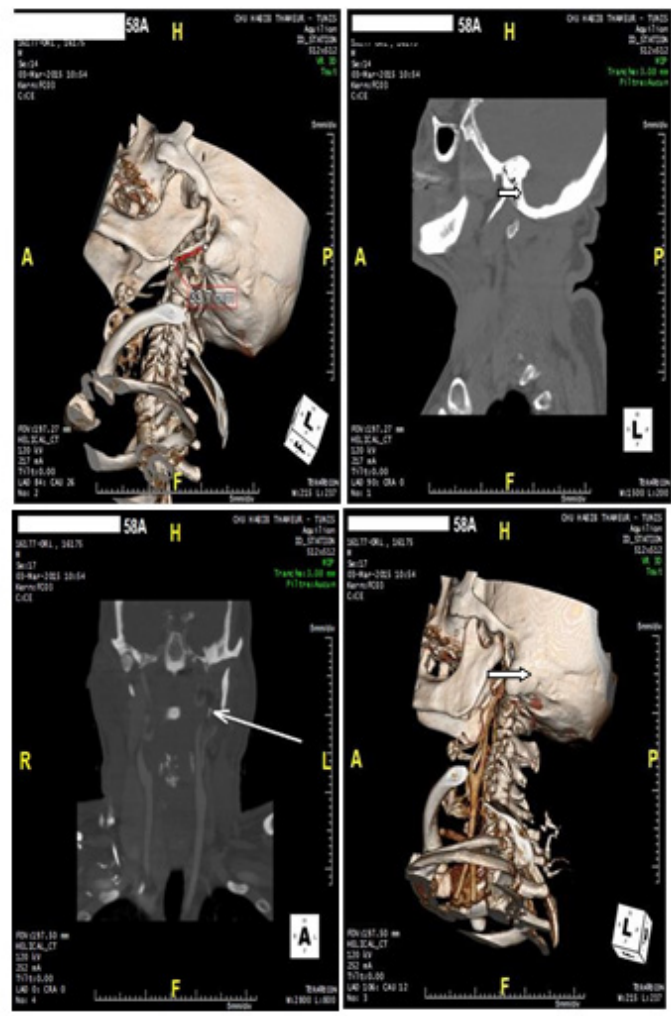

Figure IA: Reconstruction 3D styloid pro left cess; B: Sagittal; CT: elongated left styloid process

C: Coupe coronal; CT: lying left styloid process coming into contact with the carotid arteries, D: 3D reconstruction: lying left styloid process coming into contact with the carotid arteries. In réinterrogeant the patient, he says he suffered left-sided neck pain, radiating to the face. The clinical examination bilateral filling of tonsillar dimples and palpation of the styloid processes reproduced pain. 


\section{Discussion}

\section{Definition}

The styloid process is a conical bone formation that originates from the base of the skull to the underside of the mastoid. She heads down and inwards in the upper cervical region, the normal length varies between 20 and $25 \mathrm{~mm}$ in adults. The stylohyoid ligament connects the tip of the styloid process to the little horn of the hyoid bone. Eagle syndrome is a radio-clinical entity characterized by ossification stylohyoid ligament giving a long styloid process exceeding $30 \mathrm{~mm}$ in length. ${ }^{1,2}$

\section{Clinical}

Clinically, the Eagle syndrome is characterized by a large variability semiotic, making it impossible to identify a characteristic clinical picture Eagle distinguished three groups.

The first group is the "classic syndrome" involving a pharyngeal discomfort, neck pain, earache, foreign body sensation in the throat, dysphagia, distortion of taste and a odynophagia.

The second group is characterized by symptoms dominated by pain along the external carotid artery ride hence the name "of the external carotid syndrome."

The third group: is that of the chance discovery of ossification of stylohyoid ligament on a radiograph of the cervical spine or a panoramic radiograph in a clinically asymptomatic patient..$^{3-6}$

\section{Imaging}

Standard radiology shows a continuation of the process by the styloid process of bone and a pseudo-joints appearance extending from the styloid apophysis at the small horn of hyoid (Figure 2).



Figure 2 Radiopaedia elongation of the styloid process.

Figure2.Radiopaedia elongation of the styloid process.

The dental panoramic should be interpreted with caution due to high radiographic magnification level of the patient's inclination in the radio.

$\mathrm{CT}$ is the reference examination before making any surgical decision.

The evaluation of the styloid process is preferably made to the scanner after contrast injection, the scanner allows for $2 \mathrm{D}$ reconstructions in the axis of the styloid apophysis to accurately measure its length .It also assesses the thickness of the styloid process and the relationship of the styloid apophysis with surrounding vascular structures, the tonsillar fossa and the pharynx constrictors. 3D reconstructions are most useful for evaluating the spatial relationship between the styloid process and the internal carotid artery. ${ }^{4-8}$

\section{Treatment}

The surgical treatment is based on the resection of the calcified process and the release of the neurovascular structures comprimées. Cette resection is performed either by endo-oral or externally. The operating suites are generally simple marked by the relief of symptoms. Local treatment based corticosteroid injections may be initiated in patients clinically little embarrassed or refuse the operation. ${ }^{10-12}$

\section{Conclusion}

Eagle syndrome is still underestimated and misunderstood by clinicians despite its frequency, palpation of tonsillar dimples and careful analysis of cervical spine radiography and panoramic radiography can evoke the diagnosis. CT is the reference examination before making any surgical decision.

\section{Acknowledgments}

None.

\section{Conflict of interest}

None.

\section{References}

1. Williams PL. Gray's Anatomy, 38th edn. ELBS with Churchill Livingstone: London. 1999; pp. 592.

2. Sokler K, Sandev S. New classification of the styloid process length-clinical application on the biological base. Coll Anthropol. 2001;25:627-632

3. Kolagi SI, Herur A, Mutalik A. Elongated styloid process-report of two rare cases. IJAV. 2010;3:100-102.

4. Kim E, Hansen K, Frizzi J. Eagle syndrome-case report and review of literature. Ear Nose Throat J. 2008;87:631-633.

5. Murtagh RD, Caracciolo JT, Fernandez G. CT findings associated with Eagle syndrome. AJNR Am J Neuroradiol. 2001;22(7):1401-1402.

6. Gokce C, Sisman Y, Sipahioglu M. Styloid process elongation or Eagle's Syndrome: Is there any role for ectopic calcification? Eur $J$ Dent. 2008;2:224-228.

7. Permpalung N, Suksaranjit $\mathrm{P}$, Chongnarungsin $\mathrm{D}$, et al. Unveiling the hidden eagle: acute parotitis-induced eagle syndrome. $N$ Am J Med Sci. 2014;6(2):102-104.

8. Todo T, Alexander M, Stokol C, et al. Eagle syndrome revisited: Cerebrovascular complications. Ann Vasc Surg. 2012;26:729.e1-5.

9. Sandev S, Sokler K. Styloid process syndrome. Acta Stomatol Croat. 2000;34:451-456.

10. Balcioglu HA, Kilic C, Akyol M, et al. Length of the styloid process and anatomical implications for Eagle's syndrome. Folia Morphol. 2009;68(4):265-270.

11. Khandelwal S, Hada YS, Harsh A. Eagle's syndrome - a case report and review of the literature. Saudi Dent J. 2011;23(4):211-215.

12. Restrepo S, Palacios E, Rojas R. Eagle's syndrome. Ear Nose Throat J. 2002;81(10):700-701. 